\title{
Sliding Mode Control for Electrohydrostatic Actuator
}

\author{
Shi Zhengqiang, Tang Zhiyong, and Pei Zhongcai \\ School of Automation Science and Electrical Engineering, Beihang University, Beijing 100191, China \\ Correspondence should be addressed to Shi Zhengqiang; zhengq_shi@126.com
}

Received 25 April 2014; Accepted 3 September 2014; Published 28 September 2014

Academic Editor: Petko Petkov

Copyright (C) 2014 Shi Zhengqiang et al. This is an open access article distributed under the Creative Commons Attribution License, which permits unrestricted use, distribution, and reproduction in any medium, provided the original work is properly cited.

\begin{abstract}
Electrohydrostatic actuator (EHA) is a new actuator for next generation aircraft actuation system. This actuator is essentially a nonlinear system; response speed and accuracy are the main consideration. We use sliding mode control for this nonlinear system in this paper. The variable structure filter (VSF) is introduced to obtain the unmeasured states. Derivation of the VSF gain based on the reaching law is presented in this paper. To improve the response speed and accuracy, a nonlinear function is introduced to construct the nonlinear sliding surface using the estimated states generated by VSF. Simulation results show that low settling time and quick response are obtained by using the nonlinear sliding surface.
\end{abstract}

\section{Introduction}

Conventional aircraft hydraulic actuation systems are driven by the central hydraulic station. A major disadvantage of this arrangement is that the fuselage of the aircraft filled with hydraulic pipeline. The complicated pipelines increase the vulnerable areas and decrease the chances of survival in battlefield. The power by wire (PBW) technology is introduced to solve this problem. The central hydraulic station and the complicated pipelines can be removed by using this technology [1-3]. The key component is the so-called PBW actuators. The electrohydrostatic actuator (EHA) is an important one among these actuators.

Architecture of the EHA can be illustrated by Figure 1 .

In Figure 1 the brushless dc motor (1) is controlled to provide energy for the bidirection hydraulic pump (2). Then the controlled pump drives the symmetrical cylinder (8) to a given position. The pressure measurement (7) is used to compensate the load disturbance. The controller uses position measurement (9) to construct position close-loop. The accumulator (4) is used to collect and store leakage oil. Another role of the accumulator is to guarantee the positive pressure in the return oil circuit. Check valve (3) is used to implement the logic judgment according to system pressures. Bypass valve (5) is used to isolate the actuator when system fails. (6) are safety valves.
Mathematical model of the EHA is used to obtain the control laws. However design control laws to obtain desired performance of the controlled closed-loop system is a difficult task. The main reason for this problem is that the unknown disturbances, plant parameters variation, and unmodeled dynamics cannot be considered in the mathematical model. A robust control method is needed under these circumstances. One particular approach to robust controller design is the so-called sliding mode control technique. In sliding mode control, control law forces system trajectory to reach and subsequently remain on a user-chosen hyperplane. There are two main advantages to this control philosophy. Firstly, the dynamic behavior of the system can be tailored by the choice of switching function. Secondly, the closed-loop response becomes totally insensitive to matched uncertainty [4]. Robustness of this control method is mainly achieved by the high-speed switch of the nonlinear term.

The implementation of sliding mode controllers usually needs knowledge of all system states [5]. However not all the states measurements are available in the EHA. State estimation technology can be used to obtain the unmeasured states. A relative new state estimation method called variable structure filter (VSF) is used for states estimation in this paper. Unlike the sliding mode observer, variable structure filter uses predictor-corrector strategy for states estimation. The mathematical model takes the role of predictor. For 


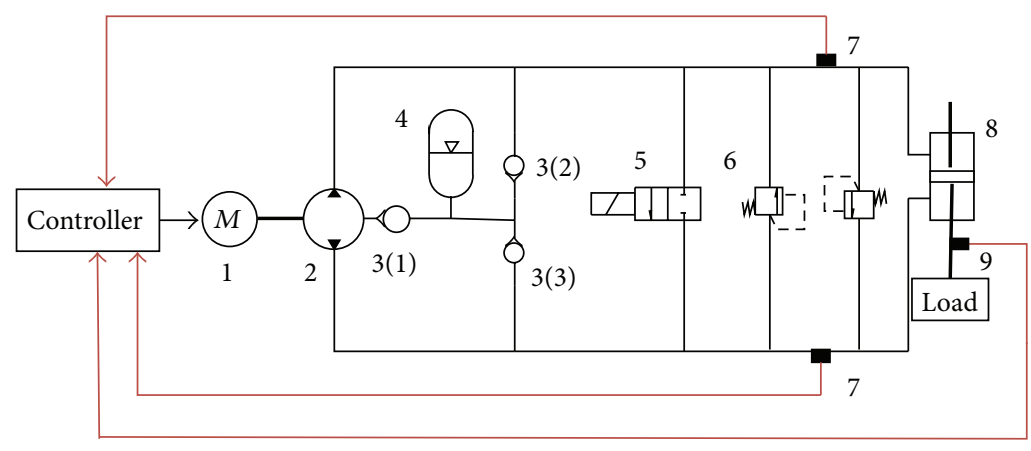

FIGURE 1: Schematic diagram of EHA.

corrector in the VSF, discontinuous component called VSF gain is used [6-9]. The VSF gain will be derived using the discrete reaching law in this paper.

In sliding mode control dynamic performances are determined by the sliding surface. There are several methods for choosing the sliding surface such as pole placement, quadratic minimization, and eigenstructure assignment [4, $10,11]$. All these methods choose the sliding surface as the linear combination of system states. Once the sliding surface is fixed, then damping ratio of the closed-loop system is fixed. However to obtain low settling time and quick response, damping ratio of the system should be changed from its initial low value to final high value [12]. This is the motivation to design a nonlinear sliding surface. References [13-15] design nonlinear sliding surface by using the principle of composite nonlinear control. In this paper, a nonlinear function is introduced to construct the nonlinear surface in a direct way.

The paper is organized as follows. In Section 2, a mathematical model of the EHA is derived for the controller design. The overall structure of the controller and the reaching law are described in Section 3. The variable structure filter and derivation of the VSF gain are described in Section 4. In Section 5, design of sliding mode control that uses nonlinear sliding surface is presented. The simulation results are considered in Section 6. Finally, in Section 7, some conclusions are given.

\section{Mathematical Model}

Ignore external leakage and the change of pump volume, flow equation of the pump can be written as follows:

$$
Q_{\mathrm{PL}}=\frac{Q_{a}+Q_{b}}{2}=D_{p} \omega-\zeta\left(P_{a}-P_{b}\right)
$$

In (1), $Q_{\mathrm{PL}}$ is the average flow of the pump. $P_{a}$ and $P_{b}$ are pump ports pressures. $Q_{a}$ and $Q_{b}$ are pump ports flows, $D_{p}$ is pump volumetric displacement, $\omega$ is speed of the pump, and $\zeta$ is the leakage coefficient of the pump.
Ignore internal and external leakage, flow equation of the two chambers of the symmetrical cylinder can be written as follows:

$$
\begin{aligned}
& Q_{1}=A \dot{y}+\frac{V_{0}+A y}{\beta_{e}} \frac{d P_{1}}{d t}, \\
& Q_{2}=A \dot{y}-\frac{V_{0}-A y}{\beta_{e}} \frac{d P_{2}}{d t} .
\end{aligned}
$$

In (2) $Q_{1}$ is the rate flow into the cylinder, $Q_{2}$ is the rate flow out of the cylinder, $P_{1}$ and $P_{2}$ are cylinder chambers pressures, $A$ is the piston area of the cylinder, $V_{0}$ is the initial volume of the cylinder, $\beta_{e}$ is the effective bulk modulus of hydraulic oil, and $y$ is the piston position.

Average flow of the cylinder is

$$
Q_{\mathrm{AL}}=\frac{Q_{1}+Q_{2}}{2} \text {. }
$$

Because $Q_{\mathrm{PL}}=Q_{\mathrm{AL}}$, then

$$
\begin{aligned}
& D_{p} \omega-\zeta\left(P_{a}-P_{b}\right) \\
& \quad=A \dot{y}+\frac{V_{0}}{2 \beta_{e}}\left(\frac{d P_{1}}{d t}-\frac{d P_{2}}{d t}\right)+\frac{A y}{2 \beta_{e}}\left(\frac{d P_{1}}{d t}+\frac{d P_{2}}{d t}\right) .
\end{aligned}
$$

Because the cylinder is symmetrical, then $d P_{1} / d t=$ $-d P_{2} / d t$. Pump outlet pressure $P_{a}$ and inlet pressure $P_{b}$ are equal to cylinder inlet pressure $P_{1}$ and outlet pressure $P_{2}$, respectively. Equation (4) can be rewritten as follows:

$$
D_{p} \omega=A \dot{y}+\frac{V}{2 \beta_{e}}\left(\frac{d P_{1}}{d t}-\frac{d P_{2}}{d t}\right)+\zeta\left(P_{1}-P_{2}\right) \text {. }
$$

Force equation of the cylinder is

$$
F=\left(P_{1}-P_{2}\right) \cdot A=M \cdot \ddot{y}+B \cdot \dot{y} .
$$

In (6), $M$ is mass of the load and $B$ is the viscous friction coefficient.

From (6), we get

$$
\left(\frac{d P_{1}}{d t}-\frac{d P_{2}}{d t}\right)=\frac{M}{A} \dddot{y}+\frac{B}{A} \ddot{y} .
$$


Substituting (6) and (7) into (5), we get

$$
D_{p} \omega=A \dot{y}+\frac{V}{2 \beta_{e} A}(M \ddot{y}+B \ddot{y})+\frac{\zeta}{A}(M \cdot \ddot{y}+B \cdot \dot{y}) \text {. }
$$

Do Laplace transforms to (8); then the linear model of the pump cylinder can be written as follows:

$$
\frac{y}{\omega}=\frac{\left(D_{p} / A\right) \omega_{n}^{2}}{s\left(s^{2}+2 \xi_{n} \omega_{n} s+\omega_{n}^{2}\right)}
$$

$$
\operatorname{In}(9), \omega_{n}=\sqrt{2 \beta_{e} A^{2} / V_{0} M} \text { and } \xi_{n}=(\zeta / A) \sqrt{\left(M \cdot \beta_{e}\right) / 2 V_{0}}+
$$
$(B / 2 A) \sqrt{V_{0} / 2 \beta_{e} M}$.

Response of the motor is much faster than the hydraulic part in the EHA. Speed of the motor can be expressed as follows:

$$
\omega=K_{a} u
$$

In (10), $K_{a}$ is the proportional gain. Then linear model of the EHA can be written as follows:

$$
\frac{y}{u}=\frac{K_{z} \omega_{n}^{2}}{s\left(s^{2}+2 \xi_{n} \omega_{n} s+\omega_{n}^{2}\right)} .
$$

In (11), $K_{z}=K_{a}\left(D_{p} / A\right)$. Choose position, velocity, and acceleration as the states variables. Convert (11) into discrete state space model and use $\xi$ to denote the lumped uncertainty in the actual EHA system. The overall nonlinear discrete state space model can be expressed as follows:

$$
\begin{gathered}
\mathbf{x}_{k+1}=\mathbf{A} \mathbf{x}_{k}+\mathbf{B} u_{k}+\mathbf{D} \xi_{k}, \\
\mathbf{y}_{k}=\mathbf{C} \mathbf{x}_{k} .
\end{gathered}
$$

In (12), $\mathbf{A}=\left[\begin{array}{ccc}1 & \tau & 0 \\ 0 & 1 & \tau \\ 0 & -\omega_{n}^{2} \tau & \left(1-2 \xi_{n} \omega_{n} \tau\right)\end{array}\right], \mathbf{B}=\left[\begin{array}{c}0 \\ 0 \\ K_{z} \omega_{n}^{2} \tau\end{array}\right], \mathbf{C}=$ $\left[\begin{array}{lll}1 & 0 & 0\end{array}\right], \mathbf{D}=\left[\begin{array}{lll}1 & 0 & 0\end{array}\right]^{T}$, and $\tau$ is the sampling time.

\section{Preliminary}

The first step to construct a sliding mode controller is to obtain all the states in system (12). The model used for states estimation can be expressed as follows:

$$
\begin{gathered}
\widehat{\mathbf{x}}_{k+1}=\mathbf{A} \widehat{\mathbf{x}}_{k}+\mathbf{B} \mathbf{u}_{k}, \\
\widehat{\mathbf{y}}_{k}=\mathbf{C} \widehat{\mathbf{x}}_{k} .
\end{gathered}
$$

The variable structure filter is used to force the states of (13) to converge to the actual states in (12). Then the estimated states are used to construct the sliding mode controller (SMC). Structure of the closed-loop system can be illustrated by Figure 2.

Since the VSF is a special form of observer, the chattering can be alleviated by a bypass high frequency loop shown in Figure 2. Ideal sliding mode is possible in the high frequency loop because it is entirely generated in the control software and thus does not contain any unmodeled dynamics [16].

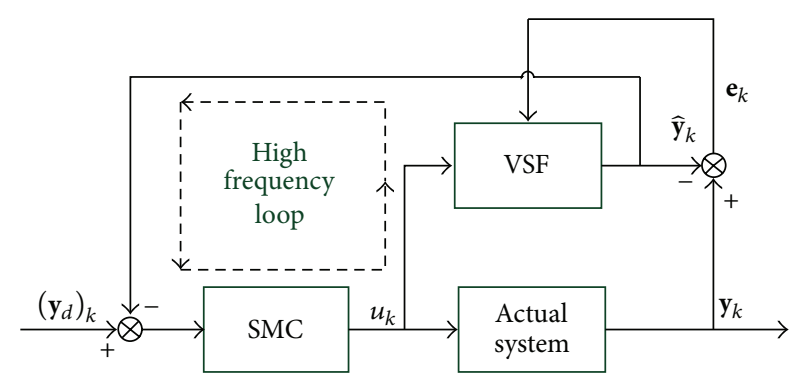

FIGURE 2: Overall structure of the sliding mode control based on variable structure filter.

The second step is to design a sliding surface. In this paper the tracking problem will be considered. Provided that the reference states is $\mathbf{x}_{d}$, error between $\mathbf{x}_{d}$ and actual states $\mathbf{x}$ is $\chi$. Then the sliding surface can be written as follows:

$$
\mathbf{S}_{k}=\psi \chi_{k}=\psi\left(\mathbf{x}_{k}-\left(\mathbf{x}_{d}\right)_{k}\right) .
$$

To obtain the control law, the last step is to specify the reaching condition to drive system trajectory to the designate sliding surface. Reaching law method is a convenient way to specify the reaching condition [17-19].

Lemma 1. Define $\Lambda$ as a diagonal matrix with elements $0<$ $1-q \tau<1 . q$ and $\varepsilon$ are positive scalars and $\tau$ is the sampling time. System trajectory $\mathbf{S}$ converges to sliding surface in finite time using the following discrete reaching law:

$$
\mathbf{S}_{k+1}=\Lambda \mathbf{S}_{k}-\varepsilon \tau \operatorname{sign}\left(\mathbf{S}_{k}\right) .
$$

Converge rate of the error can be adjusted by changing the value of $q$ and $\varepsilon$.

Proof. Define a Lyapunov function $\Gamma=\left(e_{k+1}\right)^{2}$; then

$$
\Delta \Gamma=\left(e_{k+1}\right)^{2}-\left(e_{k}\right)^{2}=\left(\Lambda^{2}-\mathbf{I}\right) e_{k}^{2}-(\varepsilon \tau \mathbf{I})^{2} .
$$

From the definition of $\Lambda$ and $\varepsilon \tau, \Delta \Gamma$ is a negative definition diagonal matrix. Adjust parameter $q$ and $\varepsilon$ will influence the elements of $\Delta \Gamma$.

The reaching law in (15) contains a linear part and a nonlinear part. The linear part is a feedback of the error at the last step. Measurement noises and unknown disturbance will bring uncertainties into the error signal in practical situation. The nonlinear part is used to overcome these uncertainties and guarantee the stability of the system.

\section{Variable Structure Filter}

Define an unregulated estimation $\widehat{\mathbf{x}}_{k}^{k-1}$ and regulated estimation $\widehat{\mathbf{x}}_{k}^{k}$ at step $k$. Using VSF gain $\mathbf{G}_{k}$ for states regulation consider the following:

$$
\widehat{\mathbf{x}}_{k}^{k}=\widehat{\mathbf{x}}_{k}^{k-1}+\mathbf{G}_{k}
$$

The unregulated states estimation $\widehat{\mathbf{x}}_{k+1}^{k}$ at step $k+1$ can be calculate using states estimation model (13):

$$
\widehat{\mathbf{x}}_{k+1}^{k}=\mathbf{A} \widehat{\mathbf{x}}_{k}^{k}+\mathbf{B} \mathbf{u}_{k}
$$


The unregulated and regulated errors between measurement output and estimation output at step $k$ are described as follows:

$$
\mathbf{e}_{k}^{k-1}=\mathbf{y}_{k}-\widehat{\mathbf{y}}_{k}^{k-1}
$$

At step $k+1$,

$$
\mathbf{e}_{k+1}^{k}=\mathbf{y}_{k+1}-\widehat{\mathbf{y}}_{k+1}^{k} .
$$

Theorem 2. Define $|\Delta|_{u}$ as the upper bound of lumped uncertainties, $|\Delta|_{u}=\left|\mathbf{C} \Delta \mathbf{A}(\mathbf{C})^{-1} \mathbf{y}_{k}\right|_{u}+\left|\mathbf{C} \Delta \mathbf{B} \mathbf{u}_{k}\right|_{u}+\left|\mathbf{C D} \xi_{k}\right|_{u}$. A gain for VSF with finite time convergence can be expressed as follows:

$$
\mathbf{G}_{k}=\mathbf{A}^{-1} \mathbf{C}^{-1}(\boldsymbol{\zeta}-\Lambda) \mathbf{e}_{k}^{k-1}+\mathbf{A}^{-1} \mathbf{C}^{-1}|\Delta|_{\mathcal{u}} \circ \operatorname{sgn}\left(\mathbf{e}_{k}^{k-1}\right) .
$$

In (21), $\zeta$ is $\mathbf{C A C}^{-1}, \bar{\zeta}$ is the matrix $\mathbf{C} \overline{\mathbf{A}} \mathbf{C}^{-1}$, and $\Delta \zeta$ is the matrix $\mathbf{C A}(\mathbf{C})^{-1}-\mathbf{C A C}^{-1}$.

Proof. Substitute $\mathbf{e}_{k+1}^{k}$ for $\mathbf{S}_{k+1}$ and $\mathbf{e}_{k}^{k-1}$ for $\mathbf{S}_{k}$ into (15); it follows that

$$
\mathbf{e}_{k+1}^{k} \circ \operatorname{sgn}\left(\mathbf{e}_{k+1}^{k}\right)=\Lambda \mathbf{e}_{k}^{k-1} \circ \operatorname{sgn}\left(\mathbf{e}_{k}^{k-1}\right)-\varepsilon \tau \operatorname{sgn}\left(\mathbf{e}_{k}^{k-1}\right),
$$

where $\circ$ is the Schur product. Define $\operatorname{sgn}\left(\mathbf{e}_{k+1}^{k}\right)=\operatorname{sgn}\left(\mathbf{e}_{k}^{k-1}\right)$. Substitute $\operatorname{sgn}\left(\mathbf{e}_{k}^{k-1}\right)$ for $\operatorname{sgn}\left(\mathbf{e}_{k+1}^{k}\right)$; it follows that

$$
\mathbf{e}_{k+1}^{k} \circ \operatorname{sgn}\left(\mathbf{e}_{k}^{k-1}\right)=\Lambda \mathbf{e}_{k}^{k-1} \circ \operatorname{sgn}\left(\mathbf{e}_{k}^{k-1}\right)-\varepsilon \tau \operatorname{sgn}\left(\mathbf{e}_{k}^{k-1}\right) .
$$

Rewrite (23) as follows:

$$
\left(\mathbf{e}_{k+1}^{k}-\Lambda \mathbf{e}_{k}^{k-1}+\varepsilon \tau \mathbf{I}\right) \circ \operatorname{sgn}\left(\mathbf{e}_{k}^{k-1}\right)=0 .
$$

An equivalent form of (24) can be expressed as follows:

$$
\operatorname{sgn}\left(\mathbf{e}_{k}^{k}-\Lambda \mathbf{e}_{k}^{k-1}+\varepsilon \tau \mathbf{I}\right)=-\operatorname{sgn}\left(\mathbf{e}_{k}^{k-1}\right) .
$$

From(12), (13), (17), (18), (19), and (20), we get

$$
\begin{aligned}
\mathbf{e}_{k+1}^{k}= & \mathbf{C}\left(\mathbf{A C}^{-1} \mathbf{y}_{k}+\mathbf{B} u_{k}+\mathbf{D} \xi_{k}\right) \\
& -\mathbf{C}\left(\mathbf{A}\left(\mathbf{C}^{-1} \widehat{\mathbf{y}}_{k}^{k-1}+\mathbf{G}_{k}\right)+\mathbf{B} \mathbf{u}_{k}\right) \\
= & \mathbf{C A}(\mathbf{C})^{-1} \mathbf{e}_{k}^{k-1}+\mathbf{C D} \xi_{k}-\mathbf{C A G}_{k} .
\end{aligned}
$$

From (26), we get

$$
\begin{aligned}
\mathbf{e}_{k+1}^{k} & -\Lambda \mathbf{e}_{k}^{k-1}+\varepsilon \tau \mathbf{I} \\
& =\left(\mathbf{C A}(\mathbf{C})^{-1}-\Lambda\right) \mathbf{e}_{k}^{k-1}+\mathbf{C D} \xi_{k}-\mathbf{C A G}_{k}+\varepsilon \tau \mathbf{I}
\end{aligned}
$$

Define

$$
\Delta_{k}=\mathrm{CD} \xi_{k}
$$

Define $|\Delta|_{u}$ as the upper bound of $\Delta_{k}$ :

$$
|\Delta|_{u}=\left|\operatorname{CD} \xi_{k}\right|_{u}
$$

Define the VSF gain as

$$
\begin{aligned}
\mathbf{G}_{k}= & \mathbf{A}^{-1} \mathbf{C}^{-1}\left(\mathbf{C A}(\mathbf{C})^{-1}-\Lambda\right)\left|\mathbf{e}_{k}^{k-1}\right| \\
& \circ \operatorname{sgn}\left(\mathbf{e}_{k}^{k-1}\right) \mathbf{A}^{-1} \mathbf{C}^{-1}\left(|\Delta|_{u}+\varepsilon \tau \mathbf{I}\right) \circ \operatorname{sgn}\left(\mathbf{e}_{k}^{k-1}\right) .
\end{aligned}
$$

Substitute (28), (29), and (30) into (26):

$$
\begin{aligned}
& \mathbf{e}_{k+1}^{k}-\Lambda \mathbf{e}_{k}^{k-1}+\varepsilon \tau \mathbf{I} \\
& \quad=\Delta_{k}-|\Delta|_{u} \circ \operatorname{sgn}\left(\mathbf{e}_{k}^{k-1}\right)+\varepsilon \tau \mathbf{I}-\varepsilon \tau \mathbf{I} \circ \operatorname{sgn}\left(\mathbf{e}_{k}^{k-1}\right) .
\end{aligned}
$$

From (31) and the definition of $|\Delta|_{\mathcal{u}}$, we can state that

$$
\operatorname{sgn}\left(\mathbf{e}_{k+1}^{k}-\Lambda \mathbf{e}_{k}^{k-1}+\varepsilon \tau \mathbf{I}\right)=-\operatorname{sgn}\left(\mathbf{e}_{k}^{k-1}\right) .
$$

Condition (25) is satisfied.

\section{Sliding Mode Control}

The system to be controlled is described in (12). Provided that the system is controllable and $\operatorname{Rank}(\mathbf{B}, \mathbf{D})=\operatorname{Rank}(\mathbf{B})$. Without loss of generality, the system can be transformed by some transformation matrix $\mathbf{T}$ into a regular form:

$$
\begin{aligned}
& \left(\mathbf{x}_{1}\right)_{k+1}=\mathbf{A}_{11}\left(\mathbf{x}_{1}\right)_{k}+\mathbf{A}_{12}\left(\mathbf{x}_{2}\right)_{k} \\
& \left(\mathbf{x}_{2}\right)_{k+1}=\mathbf{A}_{21}\left(\mathbf{x}_{1}\right)_{k}+\mathbf{A}_{22}\left(\mathbf{x}_{2}\right)_{k}+\mathbf{B}_{2} \mathbf{u}+\mathbf{D}_{2} \xi_{k} .
\end{aligned}
$$

The sliding surface in (14) can be chosen as follows:

$$
\mathbf{S}_{k}=\left[\begin{array}{ll}
\mathbf{M} & \mathbf{I}
\end{array}\right]\left[\begin{array}{l}
\left(\boldsymbol{\chi}_{1}\right)_{k} \\
\left(\boldsymbol{\chi}_{2}\right)_{k}
\end{array}\right]=\left[\begin{array}{ll}
\mathbf{M} & \mathbf{I}
\end{array}\right]\left[\begin{array}{l}
\left(\mathbf{x}_{1}\right)_{k}-\left(\mathbf{x}_{d 1}\right)_{k} \\
\left(\mathbf{x}_{2}\right)_{k}-\left(\mathbf{x}_{d 2}\right)_{k}
\end{array}\right]=0
$$
follows:

The error vector $\left(\boldsymbol{\chi}_{1}\right)_{k}$ and $\left(\boldsymbol{\chi}_{2}\right)_{k}$ can be expressed as

$$
\begin{aligned}
& \left(x_{1}\right)_{k}=\left(\mathbf{x}_{1}\right)_{k}-\left(\mathbf{x}_{d 1}\right)_{k}, \\
& \left(x_{2}\right)_{k}=\left(\mathbf{x}_{2}\right)_{k}-\left(\mathbf{x}_{d 2}\right)_{k} .
\end{aligned}
$$

Combine (26), (27), and (28); it follows that

$$
\begin{aligned}
\left(\boldsymbol{x}_{1}\right)_{k+1}= & \left(\mathbf{A}_{11}-\mathbf{A}_{12} \mathbf{M}\right)\left(\boldsymbol{\chi}_{1}\right)_{k}+\mathbf{A}_{12}(\mathbf{S})_{k} \\
& +\mathbf{A}_{11}\left(\mathbf{x}_{d 1}\right)_{k}+\mathbf{A}_{12}\left(\mathbf{x}_{d 2}\right)_{k}-\left(\mathbf{x}_{d 1}\right)_{k+1} \\
(\mathbf{S})_{k+1}= & \left(\mathbf{M}\left(\mathbf{A}_{11}-\mathbf{A}_{12} \mathbf{M}\right)+\left(\mathbf{A}_{21}-\mathbf{A}_{22} \mathbf{M}\right)\right)\left(\boldsymbol{x}_{1}\right)_{k} \\
& +\left(\mathbf{M} \mathbf{A}_{12}+\mathbf{A}_{22}\right)(\mathbf{S})_{k}+\mathbf{M} \mathbf{A}_{11}\left(\mathbf{x}_{d 1}\right)_{k} \\
& +\mathbf{M A}_{12}\left(\mathbf{x}_{d 2}\right)_{k}-\mathbf{M}\left(\mathbf{x}_{d 1}\right)_{k+1}+\mathbf{A}_{21}\left(\mathbf{x}_{d 1}\right)_{k} \\
& +\mathbf{A}_{22}\left(\mathbf{x}_{d 2}\right)_{k}-\left(\mathbf{x}_{d 2}\right)_{k+1}+\mathbf{D}_{2} \xi_{k}+\left(\mathbf{B}_{2}\right) u_{k} .
\end{aligned}
$$

Suppose that the desired trajectory $\left(\mathbf{x}_{d}\right)_{k}$ is generated by using the following system model [20]:

$$
\begin{aligned}
& \left(\mathbf{x}_{d 1}\right)_{k+1}=\mathbf{A}_{11}\left(\mathbf{x}_{d 1}\right)_{k}+\mathbf{A}_{12}\left(\mathbf{x}_{d 2}\right)_{k}, \\
& \left(\mathbf{x}_{d 2}\right)_{k+1}=\mathbf{A}_{21}\left(\mathbf{x}_{d 1}\right)_{k}+\mathbf{A}_{22}\left(\mathbf{x}_{d 2}\right)_{k}+\mathbf{B}_{2} u_{d} .
\end{aligned}
$$


Substitute (37) into (36); it follows that

$$
\begin{aligned}
\left(\chi_{1}\right)_{k+1}= & \left(\mathbf{A}_{11}-\mathbf{A}_{12} \mathbf{M}\right)\left(\boldsymbol{\chi}_{1}\right)_{k}+\mathbf{A}_{12}(\mathbf{S})_{k} \\
(\mathbf{S})_{k+1}= & \left(\mathbf{M}\left(\mathbf{A}_{11}-\mathbf{A}_{12} \mathbf{M}\right)+\left(\mathbf{A}_{21}-\mathbf{A}_{22} \mathbf{M}\right)\right)\left(\chi_{1}\right)_{k} \\
& +\left(\mathbf{M} \mathbf{A}_{12}+\mathbf{A}_{22}\right)(\mathbf{S})_{k}+\mathbf{D}_{2} \xi_{k}+\left(\mathbf{B}_{2}\right) u_{k} \\
& -\left(\mathbf{B}_{2}\right)\left(u_{d}\right)_{k} .
\end{aligned}
$$

When sliding motion takes place, then the following condition is satisfied:

$$
(\mathbf{S})_{k}=0
$$

Then (38) can be written as follows:

$$
\left(\chi_{1}\right)_{k+1}=\left(\mathbf{A}_{11}-\mathbf{A}_{12} \mathbf{M}\right)\left(\chi_{1}\right)_{k} .
$$

Equation (41) is the sliding equation. The matrix $\mathbf{M}$ can be determined using the pole placement technique. The error system in (41) is asymptotically stable when all eigenvalues of the matrix $\left(\mathbf{A}_{11}-\mathbf{A}_{12} \mathbf{M}\right)$ lie on left half of the complex plane.

5.1. Nonlinear Sliding Surface. The sliding surface in (34) can be written as follows:

$$
\mathbf{S}_{k}=\mathbf{M}\left(\chi_{1}\right)_{k}+\left(\chi_{2}\right)_{k}
$$

$\mathbf{M}$ is a linear matrix; this sliding surface is linear combination of the tracking error vectors $\left(\chi_{1}\right)_{k}$ and $\left(\chi_{2}\right)_{k}$. The damping ratio of the error system in (41) is constant value. To obtain variable damping ratio a nonlinear matrix $\Gamma(\chi)$ is introduced. $\Gamma(\chi)$ can be expressed as follows:

$$
\Gamma(\boldsymbol{\chi})=\left[\begin{array}{ccc}
\phi\left(\chi_{1}\right) & \cdots & 0 \\
\vdots & \ddots & \vdots \\
0 & \cdots & \phi\left(\chi_{m}\right)
\end{array}\right]
$$

$\phi(\chi)$ is a nonlinear function:

$$
\phi(\chi)=\alpha\left(e^{-\lambda\left|\chi_{0}\right|}-e^{-\lambda|\chi|}\right) .
$$

In (44), $\alpha>0, \lambda>0 . \chi_{0}$ is the initial tracking error. If tracking error $|\chi|$ decrease, $\phi(\chi)$ approaches $\alpha\left(e^{-\lambda\left|\chi_{0}\right|}-1\right)$. The nonlinear function $\phi(\chi)$ decreases with the decrease of the tracking error. Then we can define the nonlinear sliding surface as follows:

$$
\mathbf{S}_{k}=\left[\begin{array}{ll}
\mathbf{M}+\mathbf{A}_{12}^{-1} \Gamma(\chi) & \mathbf{I}
\end{array}\right]\left[\begin{array}{l}
\left(\boldsymbol{\chi}_{1}\right)_{k} \\
\left(\boldsymbol{\chi}_{2}\right)_{k}
\end{array}\right] .
$$

The sliding motion equation that uses this nonlinear sliding surface can be written as follows:

$$
\left(\chi_{1}\right)_{k+1}=\left(\mathbf{A}_{11}-\mathbf{A}_{12} \mathbf{M}-\Gamma(\chi)\right)\left(\chi_{1}\right)_{k} .
$$

The nonlinear matrix $\Gamma(\chi)$ does not affect the stability of the sliding motion because this matrix is positive definite.
5.2. The Control Law. Substitute $\mathbf{M}+\mathbf{A}_{12}^{-1} \Gamma(\boldsymbol{\chi})$ for $\mathbf{M}$ in (39); it follows that

$$
(\mathbf{S})_{k+1}=\widetilde{\boldsymbol{\Phi}}\left(\chi_{1}\right)_{k}+\widetilde{\mathbf{G}}(\mathbf{S})_{k}+\mathbf{D}_{2} \xi_{k}+\left(\mathbf{B}_{2}\right) u_{k}-\left(\mathbf{B}_{2}\right)\left(u_{d}\right)_{k} .
$$

The matrices $\widetilde{\boldsymbol{\Phi}}$ and $\widetilde{\mathbf{G}}$ in (47) are

$$
\begin{gathered}
\widetilde{\boldsymbol{\Phi}=}\left(\mathbf{M}+\mathbf{A}_{12}^{-1} \Gamma(\chi)\right)\left(\mathbf{A}_{11}-\mathbf{A}_{12}\left(\mathbf{M}+\mathbf{A}_{12}^{-1} \Gamma(\chi)\right)\right) \\
+\left(\mathbf{A}_{21}-\mathbf{A}_{22}\left(\mathbf{M}+\mathbf{A}_{12}^{-1} \Gamma(\chi)\right)\right) \\
\widetilde{\mathbf{G}}=\left(\left(\mathbf{M}+\mathbf{A}_{12}^{-1} \Gamma(\boldsymbol{\chi})\right) \mathbf{A}_{12}+\mathbf{A}_{22}\right) .
\end{gathered}
$$

Substitute (48) into (15); it follows that

$$
\begin{aligned}
& \widetilde{\boldsymbol{\Phi}}\left(\boldsymbol{\chi}_{1}\right)_{k}+\widetilde{\mathbf{G}}(\mathbf{S})_{k}+\mathbf{D}_{2} \xi_{k}+\left(\mathbf{B}_{2}\right) u_{k}-\left(\mathbf{B}_{2}\right)\left(u_{d}\right)_{k} \\
& \quad=\Lambda \mathbf{S}_{k}-\varepsilon \tau \operatorname{sign}\left(\mathbf{S}_{k}\right) .
\end{aligned}
$$

Define $|\xi|_{u}$ as upper bound of the uncertainty $\xi_{k}$. Then the control law can be expressed as follows:

$$
\begin{aligned}
u_{k}= & \left(\mathbf{B}_{2}\right)^{-1}(\Lambda-\widetilde{\mathbf{G}}) \mathbf{S}_{k}-\left(\mathbf{B}_{2}\right)^{-1} \widetilde{\boldsymbol{\Phi}}\left(\boldsymbol{x}_{1}\right)_{k} \\
& +\left(u_{d}\right)_{k}-\left(\mathbf{B}_{2}\right)^{-1}\left(\mathbf{D}_{2}|\xi|_{u}+\varepsilon \tau\right) \operatorname{sign}\left(\mathbf{S}_{k}\right) .
\end{aligned}
$$

\section{Simulation Results}

To demonstrate the performance of proposed sliding mode controller. Discrete state space model of the EHA is shown in (12), the parameter is $\omega_{n}=240, \xi_{n}=0.25$, and $K_{z}=100$. The model can be rewritten as follows:

$$
\begin{gathered}
\mathbf{x}_{k+1}=\left[\begin{array}{ccc}
1 & 0.001 & 0 \\
0 & 1 & 0.001 \\
0 & -57.6 & 0.88
\end{array}\right] \mathbf{x}_{k}+\left[\begin{array}{c}
0 \\
0 \\
5760
\end{array}\right] \mathbf{u}_{k}+\left[\begin{array}{l}
0 \\
0 \\
1
\end{array}\right] \xi_{k} \\
\mathbf{y}_{k}=\left[\begin{array}{lll}
1 & 0 & 0
\end{array}\right] \mathbf{x}_{k} .
\end{gathered}
$$

Provided that $\xi$ is random signal. Standard deviation of $\xi$ is 0.15 . A position step signal is used in the simulation. Estimated states are shown in Figure 3.

In Figures 3, 4, and 5 the blue lines are estimated states and the black lines are actual states. The red line in Figure 3 is the reference position. Note that the position estimation is close to the actual position. The main reason is that the position measurement is available in the EHA system. As can be seen from Figure 6, the two elements of the VSF gain show high frequency chattering behavior.

Low settling time and quick response can be obtained by using nonlinear sliding surface. To illustrate the performance of the sliding model control using nonlinear sliding surface, we choose three different sliding surface:

$$
\begin{aligned}
& \text { sliding surface } 1: \mathbf{M}=\left[\begin{array}{ll}
20 & 10
\end{array}\right], \\
& \text { sliding surface 2: } \mathbf{M}=\left[\begin{array}{ll}
40 & 10
\end{array}\right], \\
& \text { sliding surface } 3:
\end{aligned}
$$

M

$$
=\left[20+260\left(e^{-1.5\left|\left(\chi_{1}\right)_{0}\right|}-e^{-1.5\left|\chi_{1}\right|}\right) 8+10\left(e^{-1.5\left|\left(\chi_{2}\right)_{0}\right|}-e^{-1.5\left|\chi_{2}\right|}\right)\right] .
$$




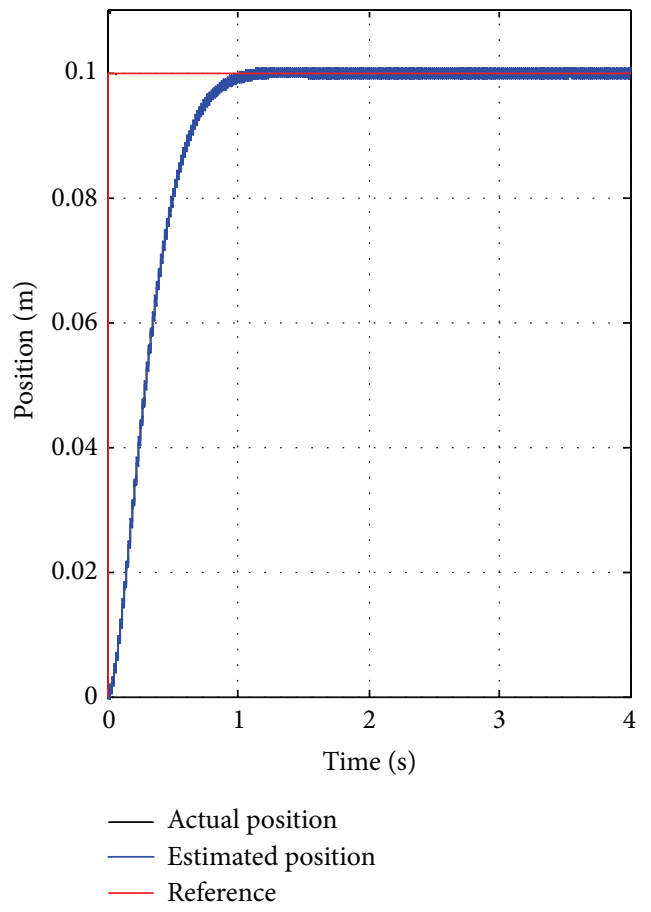

(a) Position step response of the EHA

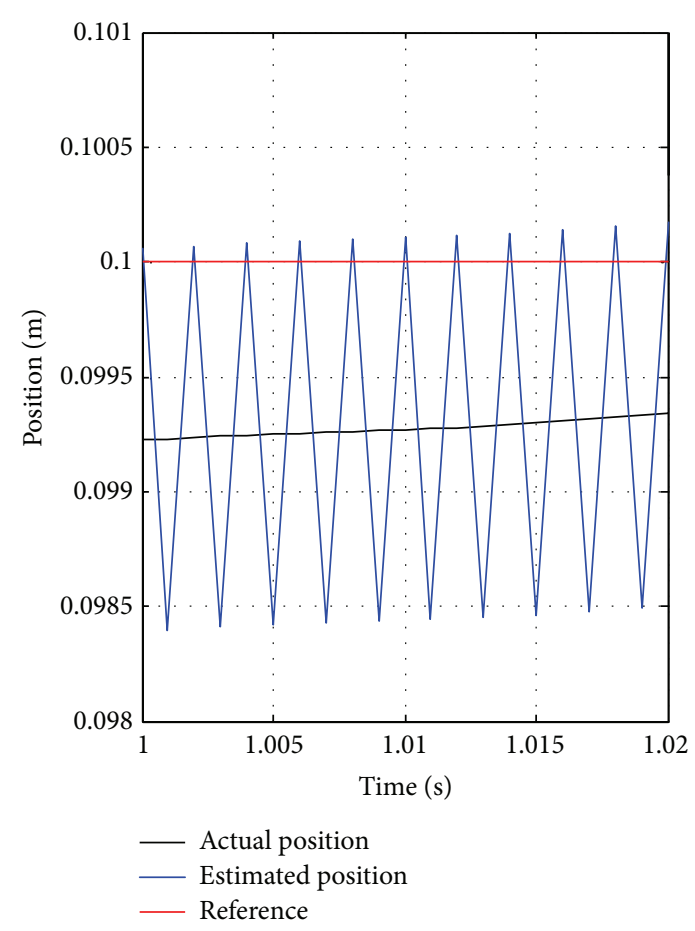

(b) Partial enlargement

FIgURE 3: Actual and estimated position of the EHA.

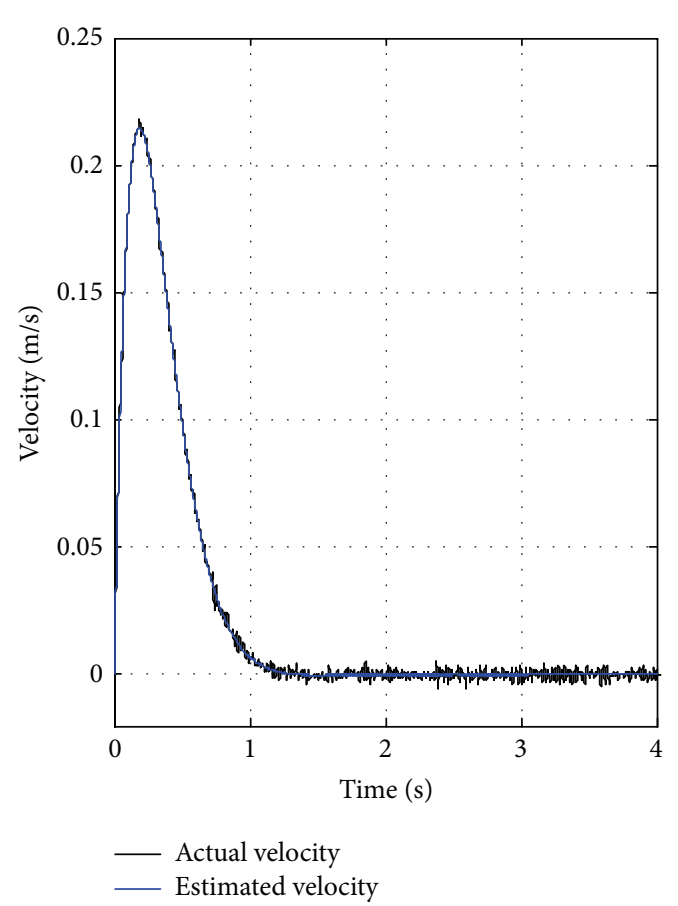

(a) Actual and estimated velocity of the EHA

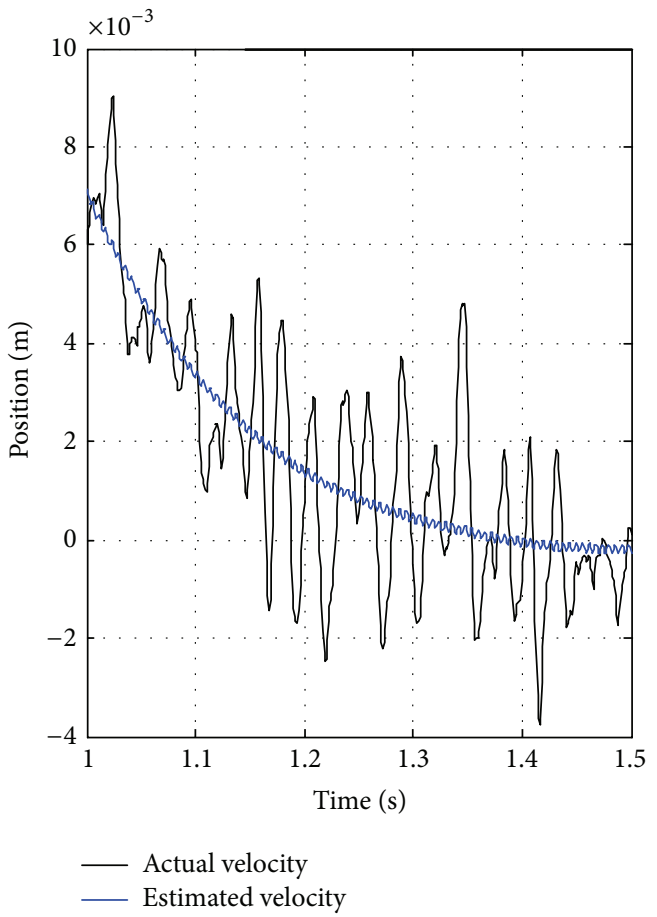

(b) Partial enlargement

FIgURE 4: Actual and estimated velocity of the EHA. 


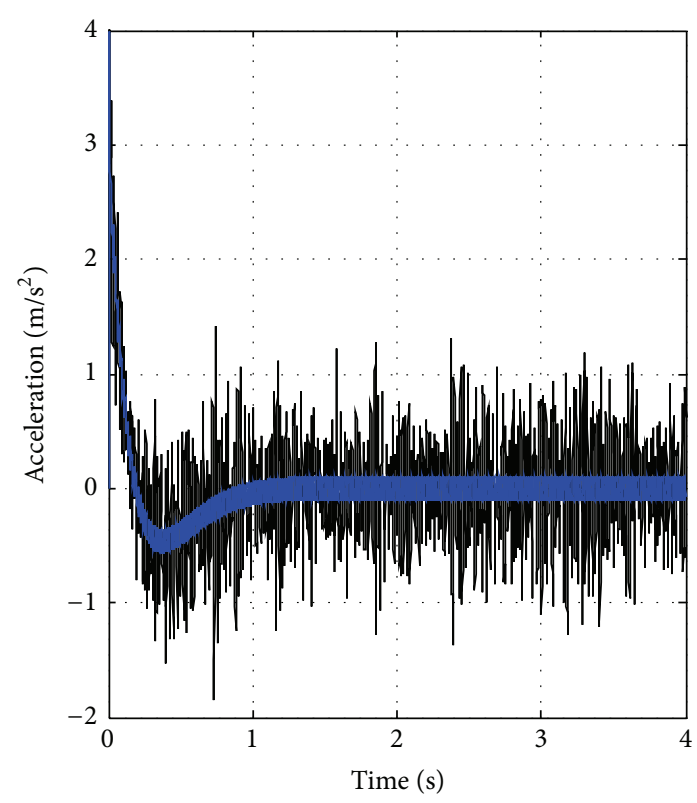

- Actual acceleration

_ Estimated acceleration

(a) Actual and estimated acceleration of the EHA

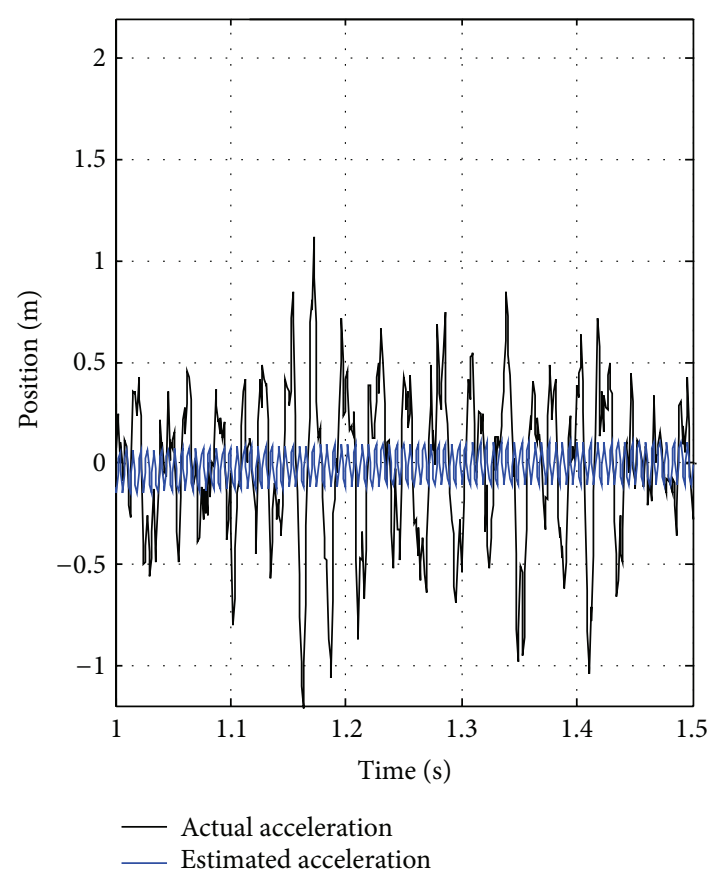

(b) Partial enlargement

FIGURE 5: Actual and estimated acceleration of the EHA.

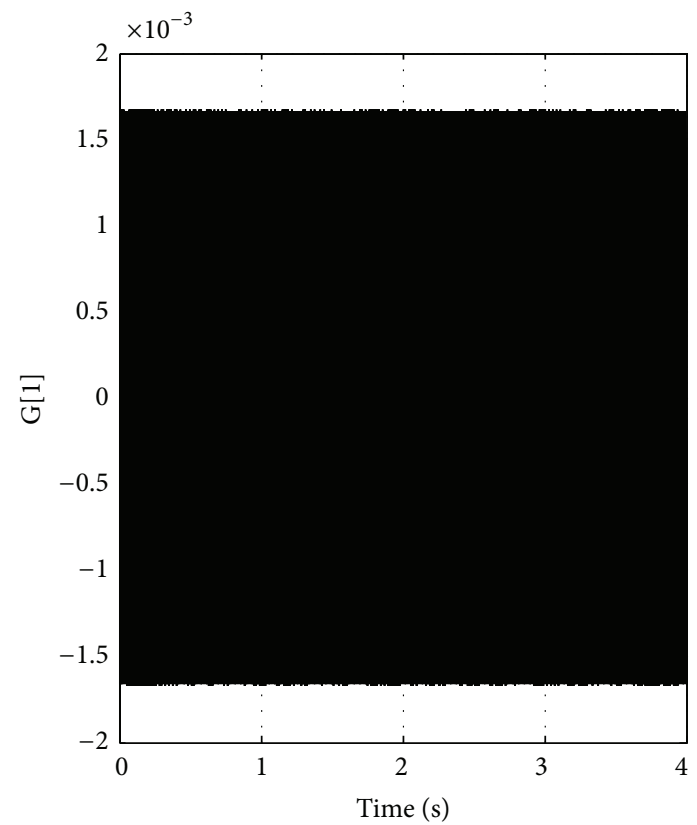

(a) First element of the VSF gain G

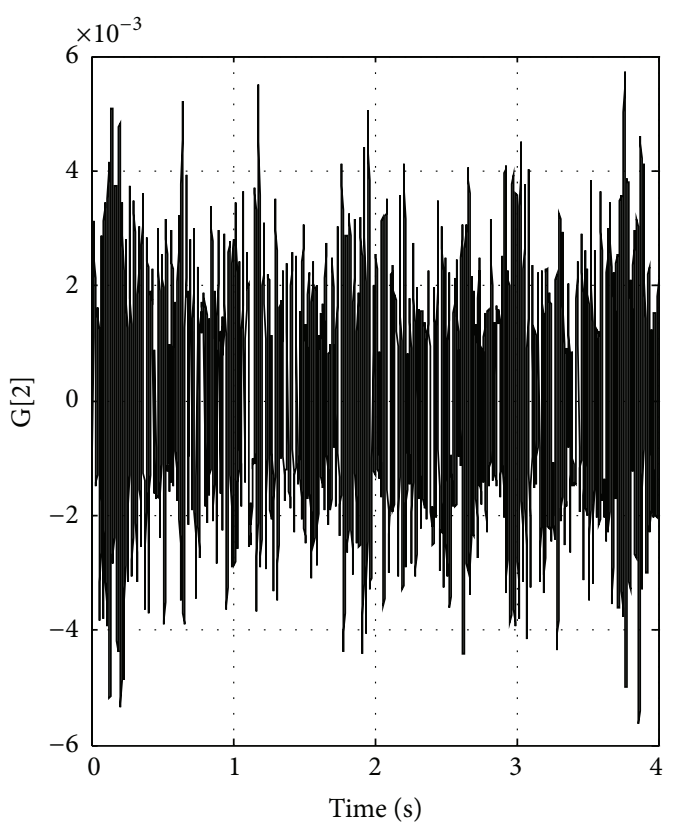

(b) Second element of the VSF gain G

FIgURE 6: Chattering behavior of the elements of the VSF gain.

Figure 7 is comparison of step response of the closed-loop system with the sliding mode controller using different sliding surface.

As shown in Figure 7, it is clear that the sliding mode controller that uses the nonlinear sliding surface has a better performance.
Primary mission of the EHA is to track a given position trajectory. Choose two sliding surface; the linear sliding surface 1 is

$$
\mathbf{S}_{k}=50\left(\chi_{1}\right)_{k}+10\left(\chi_{2}\right)_{k}+\left(\chi_{3}\right)_{k} \text {. }
$$




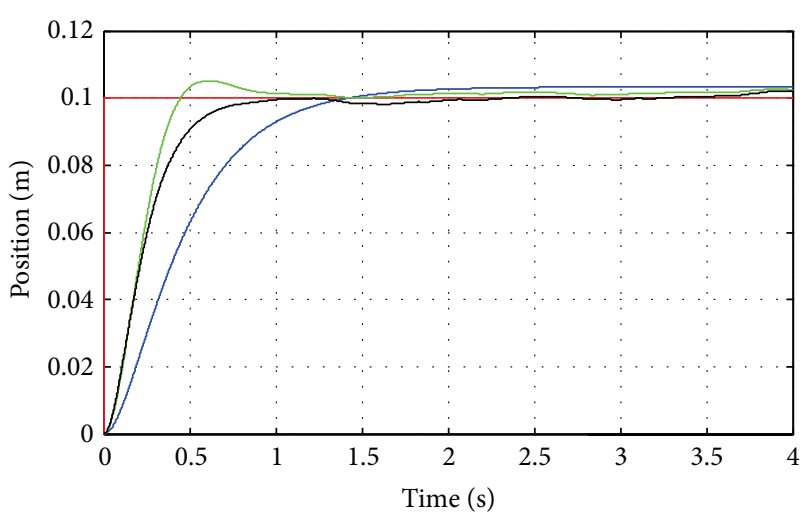

- Reference

_ Sliding surface 1

_ Sliding surface 2

_ Sliding surface 3

Figure 7: Step response using different sliding surface.

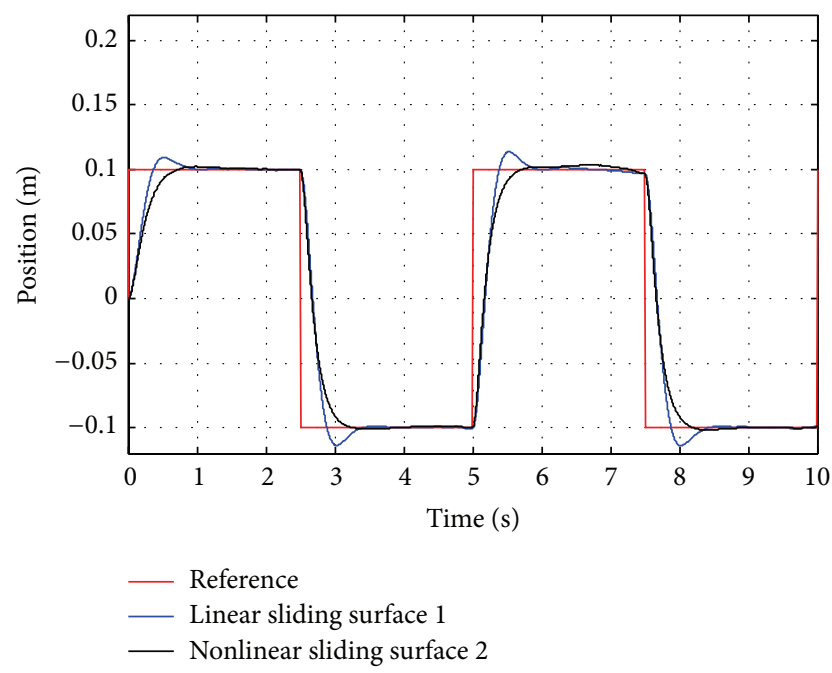

FIGURE 8: Comparison of the tracking performance.

The nonlinear sliding surface 2 is

$$
\begin{aligned}
\mathbf{S}_{k}= & \left(15+270\left(e^{-1.5\left|\left(\chi_{1}\right)_{0}\right|}-e^{-1.5\left|\chi_{1}\right|}\right)\right)\left(\chi_{1}\right)_{k} \\
& +\left(8+10\left(e^{-1.5\left|\left(\chi_{1}\right)_{0}\right|}-e^{-1.5\left|\chi_{1}\right|}\right)\right)\left(\chi_{2}\right)_{k}+\left(\chi_{3}\right)_{k} .
\end{aligned}
$$

We use a square signal as the reference. Comparison of the tracking performance is shown in Figure 8. Comparison of the tracking error is shown in Figure 9. As shown in these figures, tracking performance is improved by using the nonlinear sliding surface.

Actually the sliding mode controller used in this paper can drive the EHA to given positon more smooth than the traditional PID controller. Postions of the EHA with PID controller and SMC controller are shown in Figure 10. Reponse speed and accurance are close to each other. Velocities of the EHA with these two different controllers are shown in Figure 11. From Figure 11 we can clearly see that the velocity is more smooth when using the SMC controller.

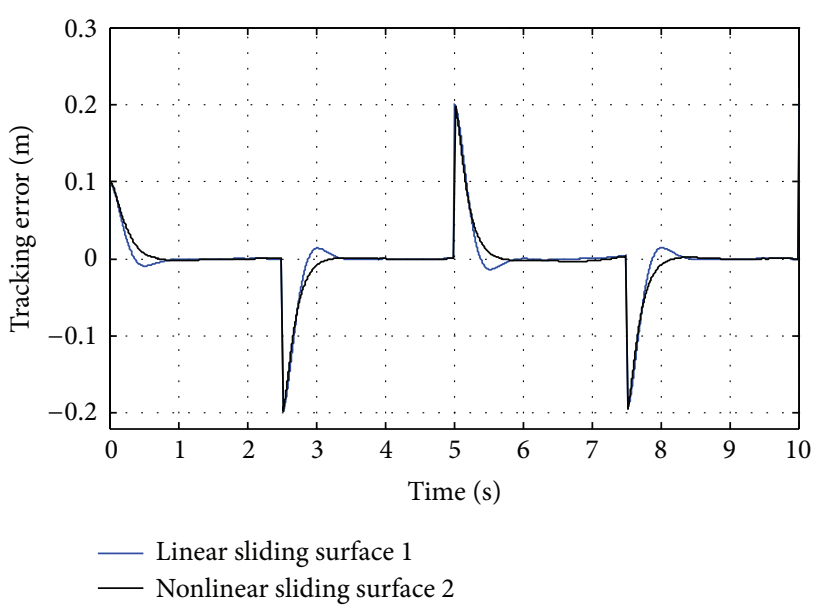

FIGURE 9: Comparison of the tracking error.

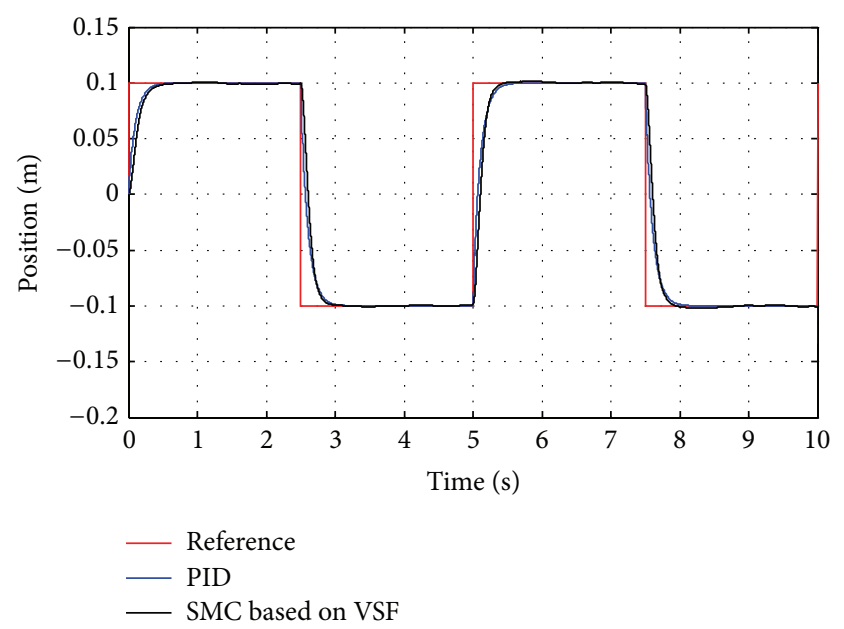

Figure 10: Comparison of the tracking positions when using different controllers.

The comparsion of the controllers output signals are shown in Figure 12. Output signal of the PID controller has a sudden change; this behavior will decrease the lifespan of the servo motor. The output signal of the SMC controller is more smooth to accomplish the same task.

\section{Conclusion}

In this paper, variable structure filter is introduced to estimate unmeasured states of the electrohydrostatic actuator. The VSF gain is derived by using the reaching law method. The variable structure with this gain has the feature of finite time convergence. Then the estimated states are used to design the sliding mode controller for the EHA. To improve the tracking performance a nonlinear function is introduced to constructed the nonlinear sliding surface. Simulation results show that the closed-loop system that uses the sliding mode 


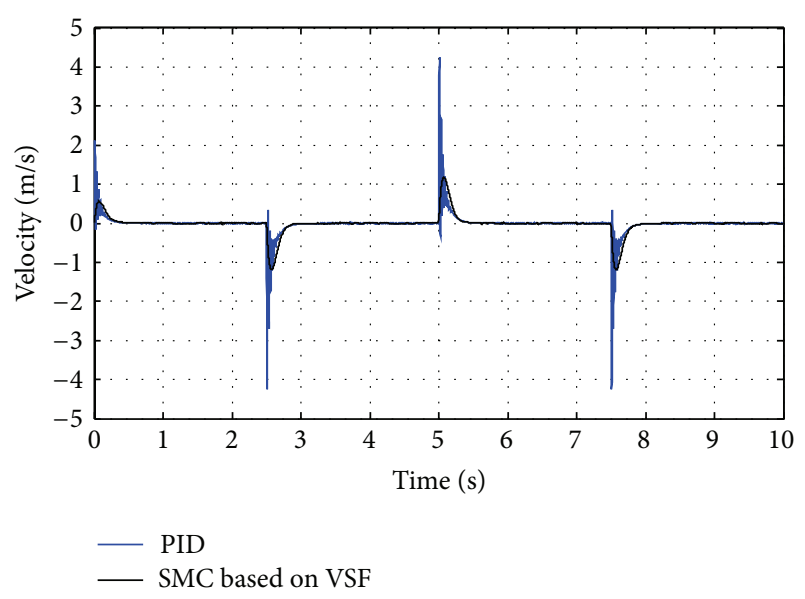

FIGURE 11: Comparison of the tracking velocities when using different controllers.

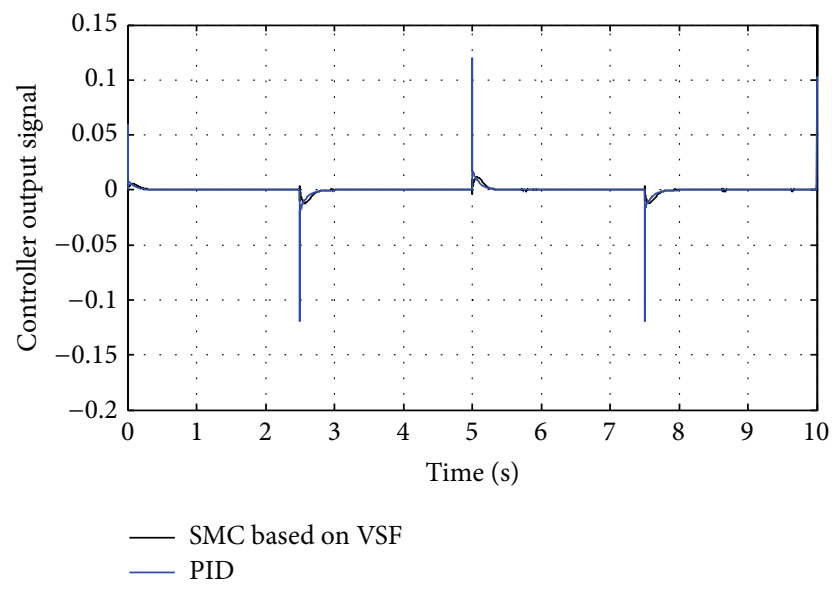

FIGURE 12: Comparison of the controllers output signals.

controller with nonlinear surface has lower settling time and faster response.

\section{Conflict of Interests}

The authors declare that there is no conflict of interests regarding the publication of this paper.

\section{References}

[1] B. Alan, "Actuator research complete," NASA the Dryden XPress, vol. 41, no. 1, 1999.

[2] N. Robert, Performance of an Electro-Hydrostatic Actuator on the F-18 Systems Research Aircraft, 1997.

[3] C. J. Stephen, D. J. Gavin, and D. David, "Flight test experience with an electromechanical actuator on the F-18 systems research aircraft," NASA Report H-2425, 2000.

[4] C. Edwards and S. K. Spurgeon, Sliding Mode Control: Theory and Applications, Taylor \& Francis, London, UK, 1998.

[5] Y. Shtessel, C. Edwards, L. Fridman, and A. Levant, Sliding Mode Control and Observation, Springer, New York, NY, USA, 2014.
[6] S. R. Habibi and R. Burton, "The variable structure filter," Journal of Dynamic Systems, Measurement and Control, vol. 125, no. 3, pp. 287-293, 2003.

[7] S. Habibi, "The extended variable structure filter," Journal of Dynamic Systems, Measurement and Control, vol. 128, no. 2, pp. 341-351, 2006.

[8] S. Habibi, "The smooth variable structure filter," Proceedings of the IEEE, vol. 95, no. 5, pp. 1026-1059, 2007.

[9] S. Wang, Integrated control and estimation based on sliding mode control applied to electrohydraulic actuator [Ph.D. thesis], University of Saskatchewan, 2007.

[10] V. I. Utkin, Sliding Modes in Control Optimization, Springer, New York, NY, USA, 1992.

[11] W. B. Gao, Foundation of Variable Structure Control, China Press of Science and Technology, Beijing, China, 1990, (Chinese).

[12] M. Thoma, Sliding Mode Control Using Novel Sliding Surfaces, Springer, Berlin, Germany, 2009.

[13] B. M. Chen, T. H. Lee, and K. Peng, "Composite nonlinear feedback control for linear systems with input saturation: theory and an application," IEEE Transactions on Automatic Control, vol. 48, no. 3, pp. 427-439, 2003.

[14] Z. Lin, M. Pachter, and S. Banda, "Toward improvement of tracking performance: nonlinear feedback for linear systems," International Journal of Control, vol. 70, no. 1, pp. 1-11, 1998.

[15] M. C. Turner, I. Postlethwaite, and D. J. Walker, "Non-linear tracking control for multivariable constrained input linear systems," International Journal of Control, vol. 73, no. 12, pp. $1160-1172,2000$

[16] V. I. Utkin, J. Guldner, and J. Shi, Sliding Mode Control in Electromechanical Systems, Taylor \& Francis, London, UK, 2009.

[17] W. Gao, Y. Wang, and A. Homaifa, "Discrete-time variable structure control systems," IEEE Transactions on Industrial Electronics, vol. 42, no. 2, pp. 117-122, 1995.

[18] W. Gao and J. C. Hung, "Variable structure control of nonlinear systems. A new approach," IEEE Transactions on Industrial Electronics, vol. 40, no. 1, pp. 45-55, 1993.

[19] J. Y. Hung, W. Gao, and J. C. Hung, "Variable structure control: a survey," IEEE Transactions on Industrial Electronics, vol. 40, no. 1, pp. 2-22, 1993.

[20] E. A. Misawa, "Discrete-time sliding mode control: the linear case," Journal of Dynamic Systems, Measurement and Control, Transactions of the ASME, vol. 119, no. 4, pp. 819-821, 1997. 

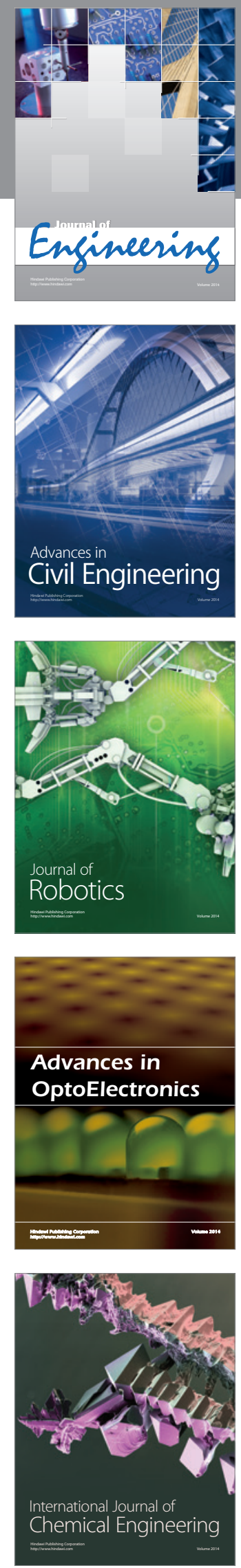

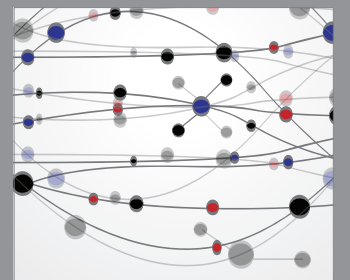

The Scientific World Journal
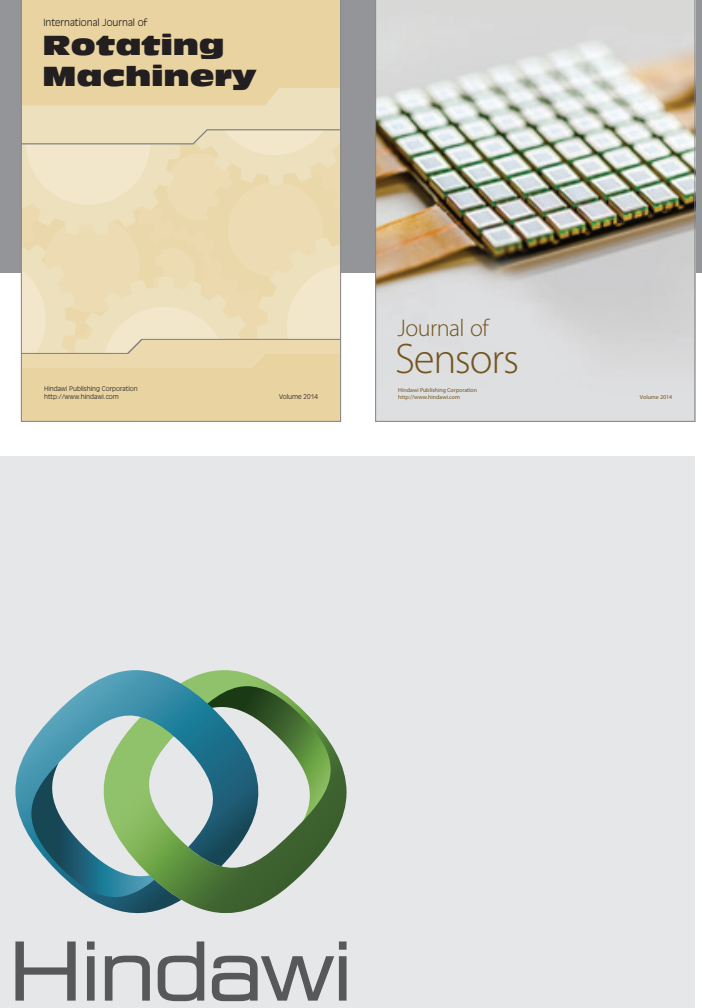

Submit your manuscripts at http://www.hindawi.com
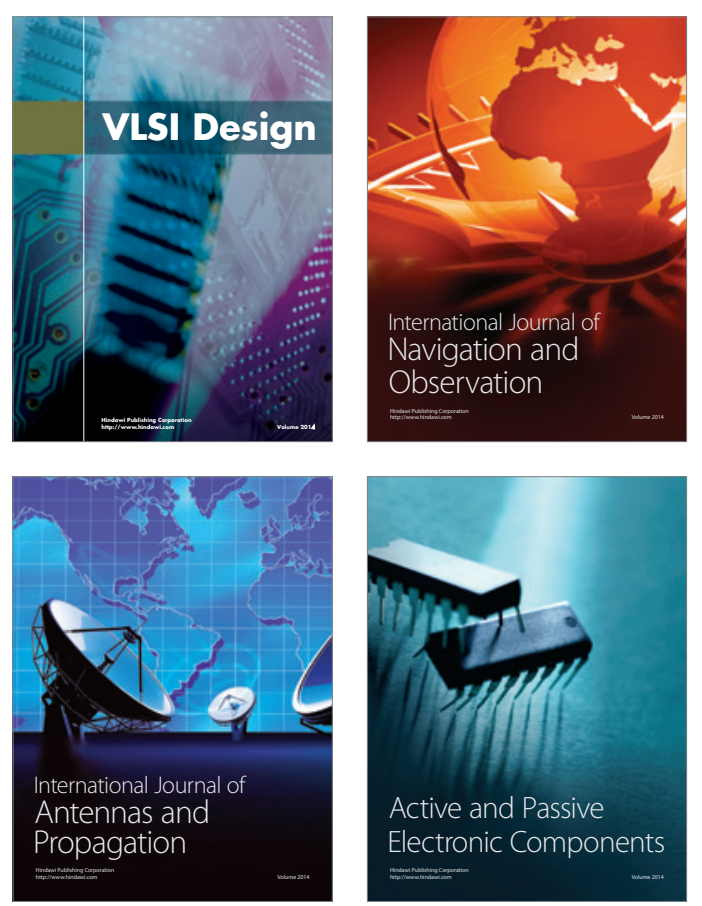
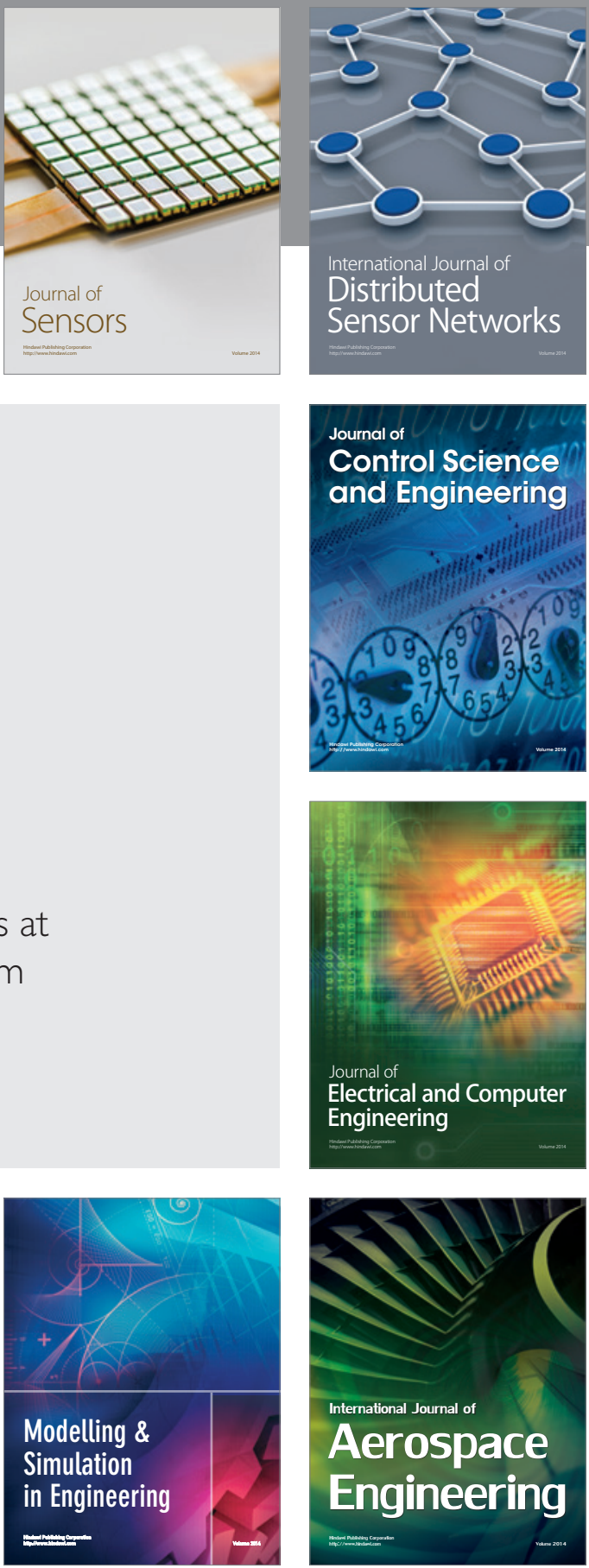

Journal of

Control Science

and Engineering
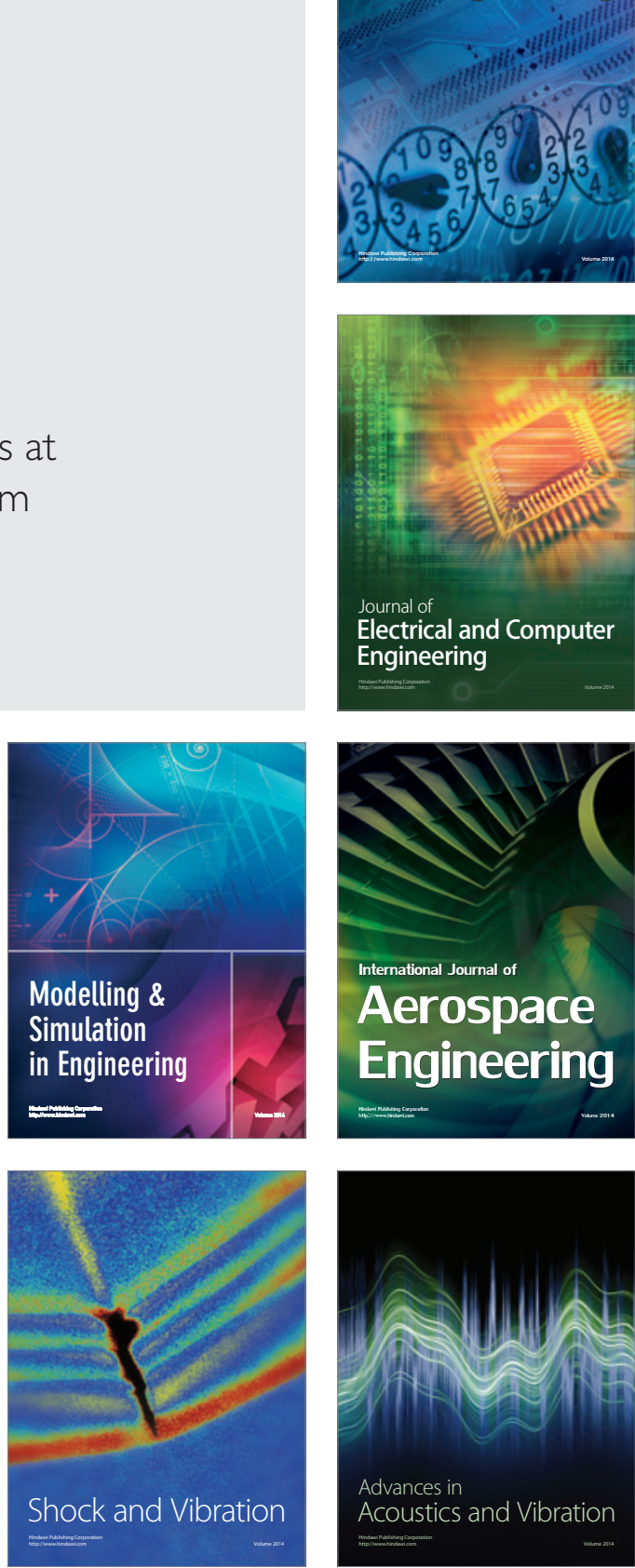